\title{
Reflexión sobre el arte latinoamericano. Aproximación testimonial
}

\author{
José Alberto de la Fuente A.
}

USACH-UCSH, Santiago, Chile. Email: Josepepe.delafuente@gmail.com

Resumen: En este artículo se hace una reflexión sobre el arte latinoamericano como contribución al conocimiento de la cultura continental, más un breve recuento de cara al Bicentenario sobre los enigmas vacíos de las nuevas expresiones y el fenómeno de la postproducción vinculado al planteamiento de Néstor García Canclini sobre La sociedad sin relato, antropología y estética de la inminencia. En las artes y en las expresiones literarias se plasman identidades y constituyen un complemento fundamental de la historia ¿El arte actual es el resultado de una sociedad sin relato?

de la inminencia.

Palabras clave: Arte latinoamericano, enigma, postproducción, estética

\section{Considerations on Latin American art. A testimonial approximation}

\begin{abstract}
This article thinks about Latin American art as a contribution to the knowledge of continental culture, and adds a brief account at the face of the Bicentennial celebration, about the empty enigmas of new expressions and the phenomenon of the postproduction linked to Nestor Garcia Canclini's approach on Society without narrative, anthropology and aesthetics of imminence. In the arts and literary expressions identities are shaped and are a vital complement of history. Is current art the result of a society without narration? imminence.

Keywords: Latin American Art, enigma, postproduction, aesthetics of

\section{Reflexão sobre arte latino-americana. Aproximação testemunhal}

Resumo: Este artigo reflete sobre a arte latino-americana como uma contribuição para o conhecimento da cultura continental, além de um breve relato do Bicentenário dos enigmas vazios de novas expressões e do fenômeno da pós ligadas a Nestor Canclini Garcia na abordagem sociedade sem antropologia narrativa e estética de iminência. Nas artes e expressões literárias identidades estão em forma e são um complemento vital A história da arte agora é o resultado de uma sociedade sem história?

Palavras-chave: Arte Latino-Americana, enigma, pós-produção, a estética da iminência. 


\section{El arte y su contribución al conocimiento}

Uno de los fundamentos culturales de la integración latinoamericana y de la presencia regional en el mundo, es la contribución de las Artes y la Literatura a través de las imágenes visuales y de las narrativas. Sin ellas, no sería posible reconocer la importancia de la fuerza simbólica en el imaginario histórico y político de los latinoamericanos; este patrimonio simbólico "es parte del perfil de nuestras sociedades y de todos sus miembros como individuos" $"$.

La producción y creación estética de la cultura mestiza aporta valiosos insumos para que el pueblo se reconozca en su identidad, consolide su memoria y aporte su inteligencia sensible para no perderse en medio de las permanentes y acuciantes preguntas sobre quiénes somos los latinoamericanos en esta transición milenaria, cuál es nuestro lugar en el mundo y cómo seguiremos enfrentando la vertiginosa globalización, cada día más acelerada por la telemática, la cibernética y la informática.

El pintor brasileño Ferreira Gullar, en 1989, nos recordó con claridad y precisión, que no hay ninguna novedad en decir que el modo de conocimiento estético difiere del modo del conocimiento científico e igualmente del filosófico. El Arte, la poesía son expresiones cuestionadoras de todo el conocimiento establecido e incluso del propio conocimiento estético. El artista es un cuestionador permanente de la cultura porque es crítico, porque privilegia la experiencia existencial y afectiva de cara al mundo conceptualizado. La conceptualización es la búsqueda de la estabilidad y del equilibrio, pero implica un distanciamiento respecto a la realidad objetiva y subjetiva. El científico, el filósofo, el sociólogo también cuestionan las culturas, pero de manera diferente al artista y al poeta. Aquellos quieren sustituir un concepto por otro, en cambio el artista y el poeta cuestionan la propia conceptualización de la realidad; se niegan a las generalizaciones que disuelven la experiencia vivida en el concepto abstracto. Su modo de conocer es un incesante recomenzar como la vida misma" ${ }^{2}$.

La América Andante como la definía Alfonso Reyes, une sus pasos en la palabra poética, en la música popular, en el carnaval, en la danza, en sus dramas y ensayos histórico-políticos, en sus grandes novelas del realismo maravilloso, social y espantoso y se transcultura, apropiándose de las vertientes universales en el lenguaje de las vanguardias que consolidan, a partir de la década 20 del siglo pasado, una conciencia de liberación y de autonomía. La ciudad de São Paulo ha sido uno de los espacios que ha contribuido, en 1922, con la histórica "Semana de Arte Modernista del 22" y en 1990 con el "Memorial de América Latina”. Historia, lengua, imágenes, poemas, etc., canalizan hibridaciones dentro del proceso de consolidación del mestizaje cultural. "La fusión, no pocas veces con mucho de confusión, de indios aborígenes, íberos, africanos y gentes de variadas latitudes, van moldeando la identidad de sociedades nuevas, generadoras de valores literarios, plásticos, arquitectónicos, musicales, coreográficos, filosóficos, ni mejores ni peores que otros, sino diferentes"3. La identidad lati- 
noamericana ha sido definida en gran parte por sus novelas y se ha ido gravando en la memoria de la emancipación a través de la pintura y del muralismo mexicano. Leopoldo Zea, en su introducción a las Fuentes de la cultura latinoamericana, insiste en la integración por la educación y la cultura; reclama una mayor difusión del pensamiento, de la literatura y demás manifestaciones estéticas.

\section{Breve recuento latinoamericano}

De cara al Bicentenario aún estamos en deuda para ofrecer un panorama completo al alcance de las mayorías de los doscientos años de Arte Latinoamericano. Un intento loable ha sido la investigación orientada por Dawn Ades de la Universidad de Yale en 1989, recopilando y ordenando las tendencias de la plástica desde 1820 hasta 1980. Su intención fue presentarle una exposición al público europeo a partir del período de los movimientos de la Independencia. El investigador reconoce que a través de la plástica, América Latina es claramente una designación de sentido político y cultural, que se opone al carácter neutro de la geografía.

La Academia Real de San Carlos en la ciudad de México, fundada en 1795, fue la primera Academia de Arte en América y la única establecida durante el régimen colonial. En este contexto, se destaca la pintura y, en particular, el óleo sobre tela Paraguay, imagen de su patria desolada (1880) de Juan Manuel Blanes, expuesto actualmente en el Museo Nacional de Artes Plásticas de Montevideo. En adelante, se va apreciando el aporte de los artistas-cronistas viajantes y la tradición empírica (ciencia y naturaleza) en América Latina posindependencia (Alexander von Humbolt, Daniel Thomas Egerton, Edward Walhouse Mark, Jean-Baptiste Debret, Johann Moritz Rugendas, Prilidiano Pueyrredón, Ferdinand Bellermann, Camille Pissarro, Carmelo Fernández, Ramón de la Sagra, Claudio Gay, Benito Panunzi, José Grijalva, José Agustín Arrieta,etc.). Luego, en México se destacará la paisajística de José María Velasco; la gráfica popular de Gabriel Vicente Gahona, José Guadalupe Posada, Manuel Manilla. Durante las primeras décadas del siglo XX, en las artes visuales, se produce una transformación radical con el modernismo vanguardista en busca y consolidación de la raíces, en pintores como Rafael Barradas, Gerardo Murillo, Diego Rivera (su famoso Paisaje zapatista), Tarsilia do Amaral, Anita Malfatti, Vicente do Rego, René Portocarrero, Emiliano di Cavalcanti, Emilia Peláez, Pedro Figari, Xul Solar, Joaquín Torres-García y aparecen las revistas Amauta (1926) (que significa en quichua hombre sabio) dirigida por José Carlos Mariátegui y la revista El Machete mexicana fundada por el Sindicato de Escultores, Pintores y Trabajadores Técnicos, órgano oficial del Partido Comunista.

Por su parte, el movimiento muralista mexicano produce el más importante arte revolucionario de carácter urbano; los muros de las ciudades y los recintos de los edificios, hablan desde las artes visuales y de las expresiones de identidad de la arquitectura colonial y poscolonial. José 
Vasconcelos, como filósofo y político revolucionario, “deja a los artistas libres para escoger sus temas; su horizonte artístico se inspira simultáneamente en los conceptos pitagóricos y en el positivismo de Comte, convencido de que la evolución de una sociedad se da a través de tres estadios, siendo el estético el más importante" ${ }^{4}$. Destacan los cuadros de Diego Rivera (El hombre, controlador del universo, 1934), de Fernando Leal ( $L a$ epopeya de Bolívar, 1930), de José Clemente Orozco (Cristo destruyendo su cruz, 1943) de Juan O’Gorman (Ciudad de México, 1942), de David Alfaro Siqueiros (Etnografía, 1939), etc. Después del desarrollo de los Talleres de la Gráfica y del Grabado Popular, se reconoce el movimiento del nativismo y del realismo social, volcado al reconocimiento y promoción de los valores indígenas. Destácanse los cuadros de Siquieros Madre campesina (1929) y Madre proletaria (1939). En la tendencia de los llamados "Universos particulares y mitos manifiestos", se constata la influencia del surrealismo de André Breton, libertad de imaginación ligada a la realidad y distante de la fantasía. El proyecto estético es "cambiar la vida, cambiar el mundo". La vida cotidiana en América Latina prueba que la realidad está repleta de cosas extraordinarias y desconcertantes. Se estacan los pintores Roberto Matta, Leonora Carrington, Tilsa Tsuchiya, Frida Kahlo, etc. De la década del 40 en adelante, se produce un salto hacia la inventiva del Arte Concreto; la pintura comienza a historiar la identidad e irrumpe La escuela del Sur, con la sobresaliente participación de Joaquín Torres-García, El Norte es el Sur, desde el cual se simboliza la corrección de la verdadera posición de América Latina en el concierto mundial Se destacan los cuadros de Antonio Berni (El mundo prometido a Juanito Laguna, 1962); de Alberto Gironella (La reina negra, 1961); de Fernando Botero (La familia presidencial, 1967) y de José Gamarra (Cinco siglos después, 1986).

Entre los países andinos se destaca Oswaldo Guayasamín, quien hacia 1952 se comienza a difundir por la exposición de más de 100 obras en el Museo de Bellas Artes de Caracas. Su obra es una transculturación de elementos formales, cubistas y temas característicos de la cultura indigenista. Su dibujo está ligado a lo popular, influido por las ideas de la "cuestión social” de la escuela mexicana. Su pintura releva la pobreza y alienación de los indios ecuatorianos, destacándose su trabajo La edad de la ira. En la composición América, mi hermano mi sangre (2006), se establece una convergencia histórica, social y política con la obra poética Canto General (1950) de Pablo Neruda. Diálogo entre pintura y poema, síntesis de la historia de la conquista, del imperio, la sobrevivencia y la revolución en América Latina. Los poemas potencian el sentido de las pinturas, y las pinturas hablan desde el carácter del pintor con el patetismo que consiguen comunicar los genios del espacio, del color y del movimiento. Las imágenes amarillas, rojizas, anaranjadas, blanquecinas y negras, cristalizan en las manchas y trazos el estado de violencia y exclusión, el empeño desigual y sin tregua de los imperios que han sometido al pueblo latinoamericano. Neruda complementa con su voz en el poema América Insurrecta:

"Patria, naciste de los leñadores,

De hijos sin bautizar, de carpinteros, 
De los que dieron como un ave extraña

Una gota de sangre voladora,

Y hoy nacerás de nuevo duramente

Desde donde el traidor y el carcelero

Te creen para siempre sumergida.

Hoy nacerás del pueblo como entonces”.

Desde el reconocimiento al desarrollo de las ideas, podemos afirmar que la Vanguardia no sólo fue coherente con la función del artista de Ferreira Gullar, sino que además sistematizó una estética a través de los Manifiestos, como por ejemplo, Hoja de vanguardia sobre el estridentismo (1921) de Manuel Maples Arce; Manifiesto da Poesía Pau-Brasil (1924) de Oswald de Andrade; Manifiesto antropófago (1928) de Oswald de Andrade; Manifiesto Martín Fierro (1924); Manifiesto de la creación pura, ensayo de estética (1925) de Vicente Huidobro; Manifiesto Arte, revolución y decadencia (1926) de José Carlos Mariátegui; La Escuela del Sur (1935) de Joaquín Torres-García; La moldura, un problema de arte contemporáneo (1944) de Rhod Rothfuss; Interiorismo, neo-humanismo, neoexpresionismo (1961) de Arnold Belkin, etc.

\section{El enigma vacío o la castración de lo bello}

De la década de los 80 del siglo XX en adelante, pareciera ser que las artes visuales y en parte la poesía han perdido los espacios de intervención ideológica desalienadora frente a los embates de la mediática y del capitalismo mercantilista desregulado. Nicolás Bourriaud acuña el concepto estética relacional para explicar cómo orientarse en el caos cultural y cómo deducir de ello nuevos modos de producción. El concepto de creación artística ha sido desplazado por el de postproducción que opera desde la organización del desecho industrial, las ruinas y demás detritus del capitalismo devorador de la naturaleza y del hombre. Según Bourriaud, la "postproducción designa el conjunto de procesos efectuados sobre un material grabado: el montaje, la inclusión de otras fuentes visuales o sonoras, las voces en off, los efectos especiales. Conjunto de actividades ligadas al mundo de los servicios y del reciclaje; la postproducción pertenece, pues, al sector terciario, opuesto al sector industrial o agrícola -de producción de materias en bruto- ${ }^{5}$. La estética postmoderna no sabe cómo evitar el eclecticismo kitsch, manifestación de un gusto confuso o desprovisto de criterios sin una visión ni proyección coherente. Es la expresión del eclecticismo banalizador y consumista.

\section{La estética de la inminencia: postproducción}

Néstor García Canclini, desde la antropología, ha estudiado el fenómeno de la estética de la inminencia. Plantea que "lo que sigue dando vida al arte no es haberse vuelto posinstitucional, posnacional y pospolítico. 
Uno de los modos en que el arte sigue estando en la sociedad es trabajando con la inminencia. La inminencia no es un umbral que estamos por superar, como si uno de estos años fuéramos a convertirnos en plenamente globales, intermediales y capaces de convivir en la interculturalidad con el mínimo de política. El arte existe porque vivimos en la tensión entre lo que deseamos y lo que nos falta, entre lo que quisiéramos nombrar y es contra-

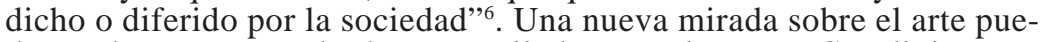
de ayudar a comprender las encrucijadas actuales. Para Canclini, aquello que para las Ciencias Sociales es difícil de explicar sobre los logros y fracasos de la globalización, el Arte formula preguntas distintas sobre qué hacen las sociedades con aquello que no encuentran respuesta en la cultura, ni en la política ni en la antropología; intento de explicación relacionado con el vacío dejado por la estéticas modernas, la fragmentación de las obras, el fugaz prestigio del canon posmoderno y las condiciones para comprender los procesos sociales. La gran producción artística latinoamericana no se acopiaba para estar en los museos; la realidad se cristalizaba para interactuar en la calle, en medio de los ojos y de los oídos de la multitud. Los proyectos artísticos posmodernos se insertan en las lógicas del mercado, los medios, las políticas o los movimientos sociales y son modificados por ellas. "La actitud prevaleciente de los públicos hacia el arte contemporáneo es la indiferencia (...) La profusión de museos, bienales y galerías dedicadas a exponer arte contemporáneo atrae a gente del mundo del arte el día de la inauguración y luego logran una modesta asistencia de fin de semana si disponen de recursos para anunciar en los medios, a nativos y turistas, que ofrecen algo excepcional" 7 .

\section{Conclusión}

En efecto, hoy en día estaríamos en una sociedad sin relato porque lo que se califica de "arte actual" no discute ni propone cambiar la vida o contribuir al desarrollo de una conciencia crítica para la transición del neoliberalismo hacia otro paradigma civilizador. Los relatos que se van instalando están expuestos y fagocitados por "una condición histórica que no les permite contribuir a organizar la diversidad en un mundo cuya interdependencia hace desear a muchos que exista" ${ }^{\text {" }}$. El compromiso de estas manifestaciones estéticas -salvo excepciones- es lo que Kant denominó "objetos construidos" siguiendo una finalidad sin fin. Las "escenas de avanzada” como suelen calificarse a las expresiones artísticas posdictaduras, sometiendo las sensibilidades a las eternas transiciones de las democracias protegidas a las democracias plenas que se niegan a concretar su cometido a riesgo de morir aplastados por la esperanza, están demasiado distantes del concepto de Arte que acuñó la UNESCO ¿Cuáles son, en tiempos de perversión y confusión de sentidos, las obras culturales de valor extraordinario que se resistan a convertirse en mercancías? Como pensaba Benjamin en su ensayo sobre el arte en la época de la reproductividad técnica, el capitalismo mercantil desregulado le sustrajo el aura a los objetos estéticos, le secuestró “la manifestación irrepetible de una lejanía”. En lo 
irrepetible, en lo singular está el sentido. Lo demás es un engaño, un enigma vacío.

(Año 2010, presentación en XI capítulo Corredor de las Ideas, Argentina, Us. Lanús-Sarmiento. Mesa: testimonios sobre Arte Latinoamericano). 
Polis, Revista Latinoamericana, Volumen 12, No 34, 2013

\section{Notas}

${ }^{1}$ Iglesias, Enrique (1999), en el "Prólogo" de Fundamentos culturales de la integración latinoamericana, página 7 de Leopoldo Castedo.

${ }^{2}$ Gullar, Ferreira, en “Indagaciones de hoy”, 1989, en revista Novamérica No 116.

${ }^{3}$ Castedo, Leopoldo (1999), Fundamentos culturales de la integración latinoamericana, página 21.

${ }^{4}$ Ades, Dawn (1989), Arte na América Latina, página 152.

${ }^{5}$ Bourriaud, Nicolás (2007), Postproducción, página 7.

${ }^{6}$ García Canclini, Néstor (2010), La sociedad sin relato, antropología y estética de la inminencia, página 182.

${ }^{7}$ Op., Cit., página 220.

${ }^{8}$ Op., Cit. Página 19. 


\section{Bibliografía}

Ades, Dawn (1997), Arte na América Latina. A era moderna, 1820-1980. Cosac \& Naify Edições. Yale University Press, 1989. (traducción Maria Thereza de Rezende Costa), São Paulo.

Andreu, Tomás y Pertuzé, Claudia (organizadores) (2006), Arte reciente en Chile. Ediciones y Publicaciones Puro Chile. Consejo Nacional de la Cultura y las Artes, FONDART, Santiago, Chile.

Blanco, Fernando A (2010), Desmemoria y perversión, privatizar lo público, mediatizar lo íntimo, administrar lo privado. Editorial Cuarto Propio, Chile.

Bourriaud, Nicolas (2007), Postproducción (segunda edición). Editor Fabián Lebenglik (traductor Silvio Mattoni), Argentina.

Castedo, Leopoldo (1999), Fundamentos culturales de la integración latinoamericana. Dolmen Ediciones, Chile.

De Sant'Anna, Affonso Romano (2008), O enigma vazio, impasse da arte e da critica. Editora Rocco Ltda., Rio de Janeiro.

García Canclini, Néstor (2010), La sociedad sin relato, antropología y estética de la inminencia. Kats Editores, Argentina.

Guayasamín, Oswaldo (2006), América, mi hermano, mi sangre. Un canto latinoamericano de dolor y resistencia. Obra bilingüe. Editada por Océano Sur.

Revista Novamérica, la revista de la patria grande, $\mathrm{N}^{\circ} 116$. Pintando a América Latina. Rio de Janeiro. http://www.novamerica.org.br

Recibido: 05.05.2011

Aceptado: 11.08.2012 